\title{
Familial infantile scoliosis associated with bilateral paralysis of conjugate gaze
}

\author{
MENACHEM GRANAT ${ }^{1}$, ZVI FRIEDMAN, AND TAMAR ALONI \\ From the Genetic Unit and Department of Ophthalmology, Rothschild University Hospital, \\ Faculty of Medicine, Technion, Haifa, Israel
}

SUMMARY A family with two sibs suffering from idiopathic infantile scoliosis associated wit bilateral paralysis of conjugate gaze is reported. Although the parental consanguinity and the involvement of patients of both sexes in this family are suggestive of an autosomal recessive mode of inheritance, a dominant or multifactorial pattern remains a possibility.

The familial association of idiopathic scoliosis and conjugate gaze paralysis has been reported in three families (Dretakis and Kondoyannis, 1974; Sharpe et al., 1975). Autosomal recessive inheritance has been suggested. We report two affected sibs in a consanguineous family where the skeletal and ocular manifestations appeared relatively early.

\section{Case reports}

A couple was referred for genetic counselling because their two children were affected with the same combination of skeletal and ocular abnormalities. The couple were double first cousins (Fig. 1).

${ }^{1}$ Dr M. Granat is a Research Fellow from the Department of Obstetrics and Gynecology. Present address: Department of Obstetrics and Gynecology, Hadassah University Hospital, Hebrew University, Jerusalem.

Received for publication 28 March 1979
The mother had given birth to another child wh@े died 40 hours after birth and was reported to have hađ 'spina bifida', but no further details were availablep A fourth gestation ended in a late spontaneou§ abortion.

The family history disclosed two materna

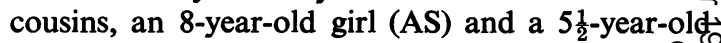
boy (AA), suffering from moderate structượ scoliosis of the thoracic spine, first noticed at he ages of $6 \frac{1}{2}$ and 4 years, respectively (Fig. 1).

\section{CASE 1 (FL)}

A $4 \frac{1}{2}$-year-old girl presented with obvious deformit of the thoracolumbar spine and some impairment os her eye movements. She was born after an uncom $\overrightarrow{\vec{B}}$ plicated term pregnancy, weighing $3500 \mathrm{~g}$ at birth A suspicion of 'strabismus' was initially noted by the parents at the age of 2 weeks. The skeletal defect was? noticed at about 6 months of age when the chilis

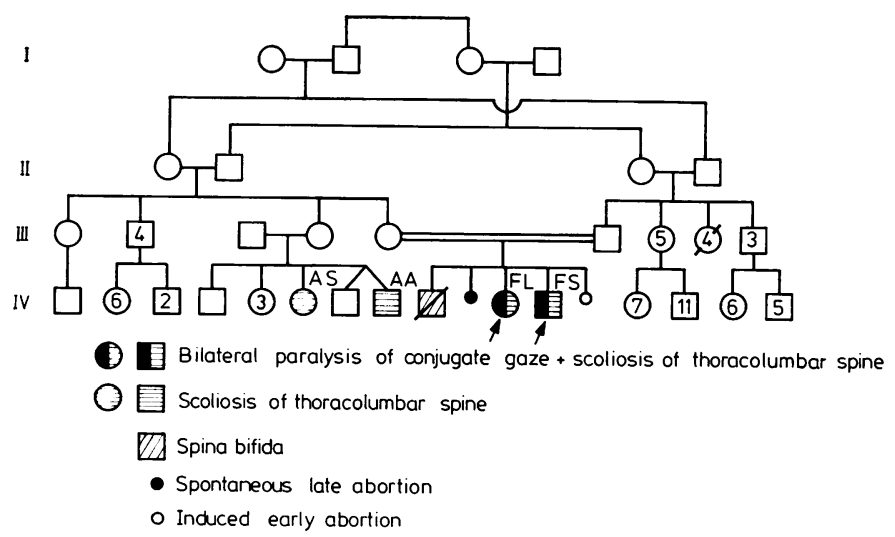

Fig. 1 Pedigree of family. 
attempted to sit. Physical findings were consistent with infantile scoliosis of the thoracolumbar spine with no underlying abnormalities of the vertebrae, associated with bilateral paralysis of conjugate gaze. Her head was markedly tilted to the left. $X$-ray of the cervical spine was normal (Fig. 2). There was no

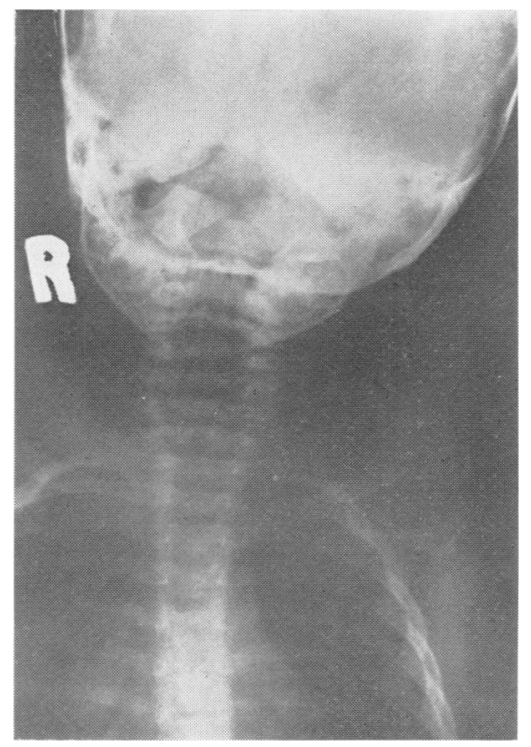

Fig. $2 X$-ray of cervical spine showing tilt to the left with no structural abnormalities (case 1).

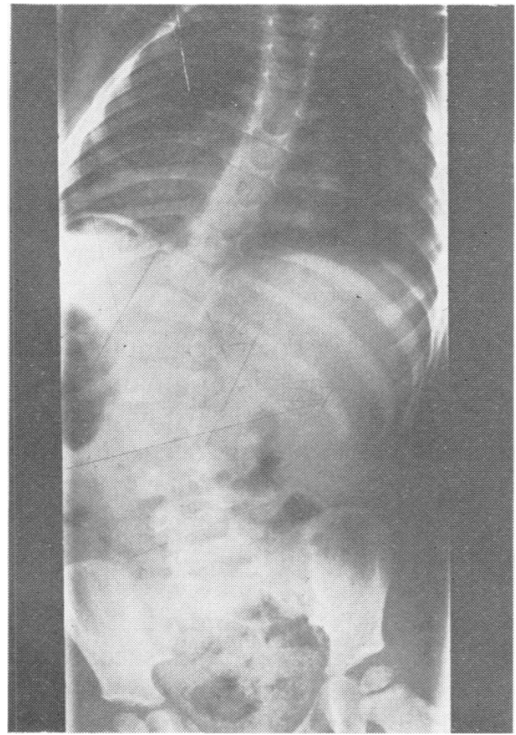

Fig. $3 X$-ray of thoracolumbar spine showing severe kyphoscoliosis (case 1). shortening of the neck muscles. A detailed reexamination at the age of $4 \frac{1}{2}$ years disclosed severe progressive kyphoscoliosis (convex to left, angle $43^{\circ}$ ) in spite of the continuous use of a Milwaukee brace (Fig. 3). The head tilt seemed to improve spontaneously.

The eye examination showed visual acuity of $3 / 7$ in each eye. The anterior segments and ocular fundi were normal. Refraction under cycloplegia showed emmetropia. There was paralysis of horizontal movements, both saccadic and slow pursuit, to both sides. Optokinetic nystagmus could not be elicited. Vestibular nystagmus, both rotational and that induced by the caloric test using ice cold water, was absent on both sides.

There was slight convergence on attempted dextroversion and levoversion. Convergence, as well as upward and downward conjugate movements, were all normal. The pupils were equal and reacted to light and to near stimuli. Intermittent unilateral blinking movements could be seen from time to time. No abnormal synkinesis could be detected.

Mental development was normal for age. Dermatoglyphic analysis did not disclose unusual findings. Neurological examination did not reveal any additional abnormalities.

CASE 2 (FS)

A $2 \frac{1}{2}$-year-old brother of case 1 was referred to the eye clinic with the suspicion of a similar impairment

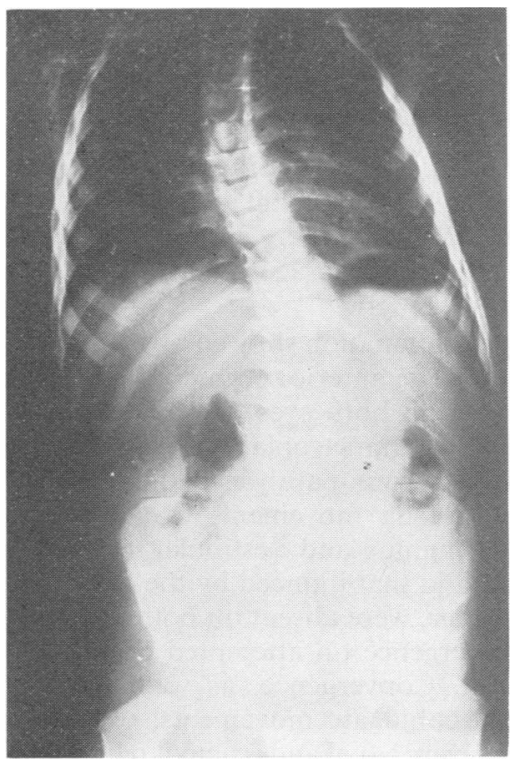

Fig. $4 \quad X$-ray of thoracolumbar spine showing severe kyphoscoliosis (case 2). 


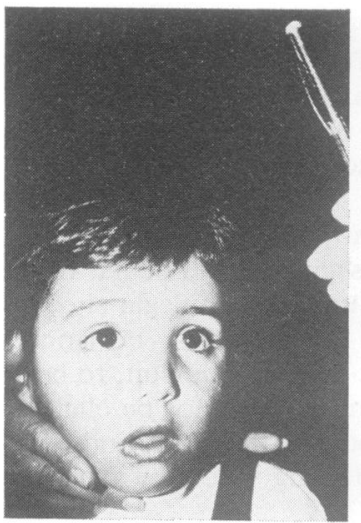

(a)

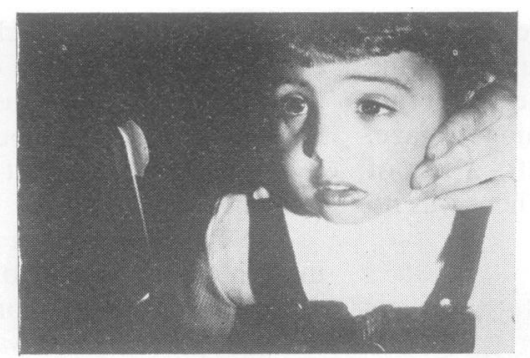

(b)

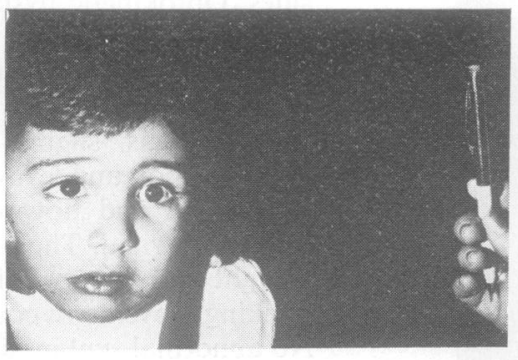

$(d)$

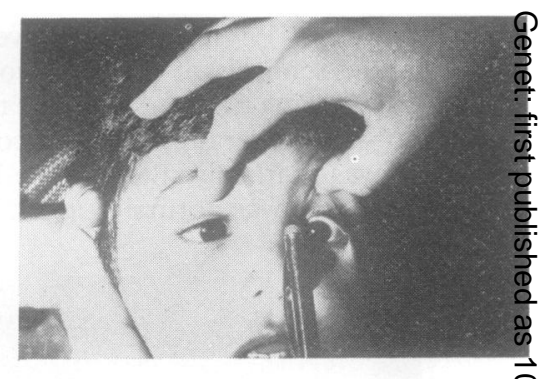

(c)

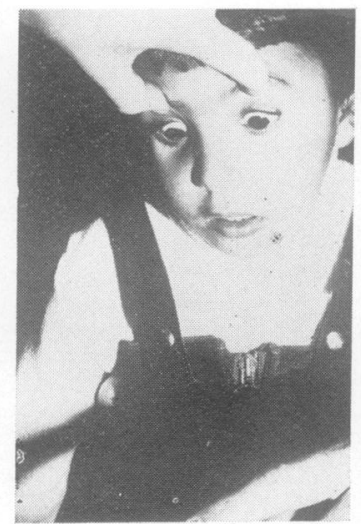

(e)

Fig. 5 Ophthalmological findings showing horizontal conjugate gaze paralysis (case 2). (a) upward gaze; (b) attempted gaze to right; $(c)$ convergence; $(d)$ attempted gaze to left; $(e)$ downward gaze.

of ocular movements. He was born after an uncomplicated term pregnancy, weighing $3750 \mathrm{~g}$. The parents suspected impaired ocular movements and a skeletal deformity at the age of one year.

The scoliosis of the thoracolumbar spine (Fig. 4) was less marked than that of his sister (convex to left, angle $13^{\circ}$ ), but severe enough to necessitate the use of a Milwaukee brace. There was also tilting of the head to the left.

The eye examination showed a visual acuity of $4 / 7$ in each eye. The anterior segments and ocular fundi were normal in both eyes. Refraction under cycloplegia showed emmetropia.

Again, there was paralysis of horizontal saccadic and slow pursuit movements to both sides. Optokinetic nystagmus and vestibular nystagmus, both rotational and that induced by the caloric test using ice cold water, were absent on both sides. There was slight convergence on attempted dextroversion and levoversion. Convergence, as well as upward and downward conjugate movements, were all normal. The pupils were equal and reacted to light and to near stimuli. Intermittent unilateral blink could occasionally be seen. No abnormal synkinesis could be detected. The ophthalmological findings are illuse trated in Fig. 5. Neurological examination was otherwise normal.

Mental development appeared average. Derma toglyphic analysis did not show unusual findings.

Physical and $x$-ray examination of the mother. showed a mild non-functional thoracic scoliosis which had not been noted previously.

\section{Discussion}

Descending pathways for horizontal saccadic an $\Phi$ smooth pursuit movements originate in the fronta and the occipital cortex, respectively, aggregate in the midbrain reticular formation, decussate in the loweg. midbrain and upper pons, and descend to the pontine paramedian reticular formation (PPRF) near the nucleus of the abducens nerve (Gay et al N 1974; Duane, 1976).

Bilateral paralysis of conjugate gaze involving both the frontomescencephalic saccadic and the occipitomescencephalic smooth pursuit systems may be caused by lesions extending between theupper braip stem region, where these two systems converge anatomically, and the PPRF. 
Since in both cases described in this report there was bilateral paralysis of both saccadic and slow pursuit horizontal movements and absence of both the vestibulo-ocular nystagmus and the oculocephalic response (doll's eye movement), it is clear that the lesion in these cases was localised in the pons at the level of the PPRF. This is supported by the fact that the vertical conjugate movements and the convergence, the pathways of which descend and synapse with the oculomotor nuclei, were all intact.

Lesions at upper areas spare the vestibulo-ocular nystagmus and the oculocephalic reflexes, whereas conjugate vertical movements and convergence may be affected.

Congenital bilateral paralysis of conjugate gaze may be sporadic (Zweifach et al., 1969) or familial (Dretakis and Kondoyannis, 1974; Sharpe et al., 1975). It may be isolated (Zweifach et al., 1969) or associated with facial palsy and other anomalies, such as are found in Möbius's syndrome.

Only three families have been previously reported where the association of bilateral conjugate gaze paralysis and idiopathic scoliosis was encountered (Dretakis and Kondoyannis, 1974; Sharpe et al., 1975). The Table summarises the clinical features found in our cases as well as in each affected sib in the families reported before (Dretakis and Kondoyannis, 1974; Sharpe et al., 1975). In the family reported here, the ocular motor manifestations were virtually identical with those described in these reports, apart from the absence of nystagmus. This may denote a similar supranuclear involvement in the pons. Our family is unique in the very early onset of scoliosis, which was therefore of the infantile type. The skeletal deformity in our cases also seems to be more severe.

Dretakis and Kondoyannis (1974) suggested that absence of postural reflexes because of neurological damage could cause the scoliosis associated with the brain stem lesions.

Sharpe et al. (1975) reported a family in which four sibs had bilateral paralysis of lateral gaze, pendular nystagmus, and progressive scoliosis. In all sibs, lateral gaze paralysis was not present at birth, but appeared during childhood or early adolescence. The electromyogram suggested a supranuclear lesion. Recessive autosomal inheritance was suggested by the authors, as indicated by absence of these abnormalities in three antecedent generations and involvement of patients of both sexes.

The close parental consanguinity in the family reported here seems to substantiate an autosomal

Table Clinical data on 4 families affected by conjugate gaze paralysis and idiopathic scoliosis

\begin{tabular}{|c|c|c|c|c|c|c|c|c|c|c|c|}
\hline \multirow{3}{*}{$\begin{array}{l}\text { Sex } \\
\text { Ocular manifestations } \\
\quad \text { Age when first noticed }(y)\end{array}$} & \multicolumn{3}{|c|}{$\begin{array}{l}\text { Family } 1 \\
\text { (Dretakis and } \\
\text { Kondoyannis, 1974) }\end{array}$} & \multicolumn{2}{|c|}{$\begin{array}{l}\text { Family } 2 \\
\text { (Dretakis and } \\
\text { Kondoyannis, } \\
\text { 1974) }\end{array}$} & \multicolumn{4}{|c|}{$\begin{array}{l}\text { Family } 3 \\
\quad \text { (Sharpe et al., 1975) }\end{array}$} & \multicolumn{2}{|c|}{$\begin{array}{l}\text { Family } 4 \\
\text { (This report) }\end{array}$} \\
\hline & $\mathbf{M}$ & $\mathbf{M}$ & $\mathrm{F}$ & $\mathbf{M}$ & $\mathbf{M}$ & $\mathbf{M}$ & $\mathbf{M}$ & $\mathrm{F}$ & $\mathbf{M}$ & $\mathbf{F}$ & $\mathbf{M}$ \\
\hline & $?$ & $?$ & $?$ & 2 & $\begin{array}{l}\text { Early } \\
\text { infancy }\end{array}$ & $\begin{array}{l}\text { Early } \\
\text { adoles- } \\
\text { cence }\end{array}$ & 8 & $\begin{array}{l}\text { Child- } \\
\text { hood }\end{array}$ & 4 & \multicolumn{2}{|c|}{2 weeks 1} \\
\hline Lateral gaze paralysis & + & + & + & + & + & + & + & + & + & + & + \\
\hline Optokinetic nystagmus & $?$ & $?$ & $?$ & $?$ & $?$ & - & - & $?$ & $?$ & - & - \\
\hline Vestibular stimulation & $?$ & $?$ & $?$ & $?$ & $?$ & - & - & $?$ & $?$ & - & - \\
\hline Convergence & $?$ & $?$ & $?$ & $?$ & $?$ & + & + & + & + & + & + \\
\hline Vertical movements & \pm & \pm & \pm & \pm & \pm & + & + & + & + & + & + \\
\hline Doll's eye movements & $?$ & $?$ & $\bar{?}$ & $?$ & $?$ & - & - & - & - & - & - \\
\hline Nystagmus & + & + & + & + & + & + & + & + & + & - & - \\
\hline Facial contractions & - & - & - & $?$ & $?$ & $\begin{array}{l}\text { Myo- } \\
\text { kymia }\end{array}$ & - & - & - & + & + \\
\hline \multirow{3}{*}{$\begin{array}{l}\text { Skeletal manifestations } \\
\text { Age when first noticed (y) } \\
\text { Scoliosis pattern }\end{array}$} & + & + & + & $?$ & $?$ & + & + & $?$ & $?$ & - & - \\
\hline & 10 & 2 & 2 & 4 & 4 & 10 & 10 & 8 & 4 & $1 / 2$ & 1 \\
\hline & \multicolumn{3}{|c|}{$\begin{array}{l}\text { Lower thoracic curve to } \\
\text { right }\end{array}$} & \multicolumn{2}{|c|}{ Same as family 1} & $\begin{array}{l}\text { Severe t } \\
\text { convex } \\
\text { to left }\end{array}$ & $\begin{array}{l}\text { hora } \\
\text { con } \\
\text { to }\end{array}$ & $?$ & $\begin{array}{l}\text { convex } \\
\text { to left }\end{array}$ & \multicolumn{2}{|c|}{$\begin{array}{l}\text { Thoracolumbar } \\
\text { convex to left } \\
\text { and kyphosis }\end{array}$} \\
\hline Associated abnormalities & \multicolumn{3}{|c|}{$\begin{array}{l}\text { Mental retardation, } \\
\text { depressed pharyngeal } \\
\text { reflexes on left, uvula } \\
\text { deviated to right, head } \\
\text { tremor }\end{array}$} & - & $\begin{array}{l}\text { Head } \\
\text { tilt, self } \\
\text { improv- } \\
\text { ing }\end{array}$ & \multicolumn{4}{|c|}{$\begin{array}{l}\text { Haematological abnormalities, } \\
\text { apparently coincidental }\end{array}$} & - & - \\
\hline Parental consanguinity & \multirow{2}{*}{\multicolumn{3}{|c|}{ Father, mild kyphosis }} & \multirow{2}{*}{\multicolumn{2}{|c|}{-}} & \multicolumn{4}{|l|}{ - } & \multirow{3}{*}{\multicolumn{2}{|c|}{$\begin{array}{l}+ \\
\text { Mother and } 2 \\
\text { maternal cousins, } \\
\text { scoliosis } \\
\text { Israel } \\
0\end{array}$}} \\
\hline Other family members affected & & & & & & One bro & ther, & ndular nys & tagmus & & \\
\hline $\begin{array}{l}\text { Parent's country of origin } \\
\text { No of unaffected sibs }\end{array}$ & \multicolumn{3}{|c|}{$\underset{4}{\text { Greece }}$} & \multicolumn{2}{|l|}{$\begin{array}{l}\text { Greece } \\
0\end{array}$} & \multicolumn{3}{|l|}{$\begin{array}{l}\text { China } \\
6\end{array}$} & & & \\
\hline
\end{tabular}


recessive mode of inheritance, as suggested in the aforementioned report (Sharpe et al., 1975). However, the presence of two maternal cousins with early onset idiopathic scoliosis, born to unrelated parents, and the mild structural scoliosis detected in the mother cast doubt on this assumption. Autosomal dominant or multifactorial inheritance, as usually implicated in familial idiopathic scoliosis (Roseborough and Wynne-Davies, 1973), may be operative in this family also. The ocular findings could be a coincidental genetic disease transmitted via a different gene. The present data are not sufficient to determine the pathogenesis of this syndrome. Additional neuro-ophthalmological surveys of patients with idiopathic infantile scoliosis may help to clarify the question of whether a syndrome of conjugate gaze paralysis and congenital scoliosis does exist, or whether the few families reported with this combination, including the one in this report, merely represent coincidences.

\section{References}

Dretakis, E. K., and Kondoyannis, P. N. (1974). Congenit scoliosis associated with encephalopathy in five children of two families. Journal of Bone and Joint Surgery, 56 1747-1750.

Duane, T. D. (1976). Clinical Ophthalmology, Vol. 2, Ch. $\vec{\oplus}$, pp. 3-8. Harper and Row, New York.

Gay, A. J., Newman, N. M., Keltner, J. L., and Stroud, M. (1974). Eye Movement Disorders, pp. 18-24. Mosb St. Louis.

Roseborough, E. J., and Wynne-Davies, R. (1973). A genetic survey of idiopathic scoliosis in Boston, Massachuset\&s. Journal of Bone and Joint Surgery, 58A, 974-982.

Sharpe, J. A., Silversides, J. L., and Blair, R. D. G. (1975). Familial paralysis of horizontal gaze. Neurology, 24 , 1035-1040.

Zweifach, P. H., Walton, D. S., and Brown, R. H. (1969). Isolated congenital horizontal gaze paralysis. Archives Ophthalmology, 81, 345-350.

Requests for reprints to Dr M. Granat, Departme of Obstetrics and Gynecology, Hadassah University Hospital, The Hebrew University, Kiryat Hadassaథ, Jerusalem, Israel. 